\title{
Evaluación por competencias en campos de conocimiento, una mirada hacia el currículo
}

Jhon Jairo Mosquera Rodas

Universidad Cooperativa de Colombia (Colombia) 



\title{
Evaluación por competencias en campos de conocimiento, una mirada hacia el currículo
}

\section{Competences evaluation in knowledge fields, a look at the curriculum}

\author{
Jhon Jairo Mosquera Rodas \\ Universidad Cooperativa de Colombia (Colombia) \\ tiempo16@hotmail.com
}

Fecha de recepción: 12 de septiembre de 2018

Fecha de aceptación: 27 de marzo de 2020

\begin{abstract}
Resumen
La investigación examina el problema de evaluar a través del modelo por competencias empleando la teoría de Biggs, teniendo encuenta tres campos de conocimiento desde el enfoque crítico, presentando finalmente un tercero, que muestra los resultados de la investigación desde la configuración evaluativa e interpretativa del proceso evaluativo por competencias. Luego de lo anterior, se aplica el método hermenéutico, empleando la perspectiva Gademariana, partiendo de la adaptación propuesta por (Noriega, 2002, pp. 1-8), centrada en el análisis textual desde el aspecto educativo, a través de los tres campos de conocimiento relacionados con el contexto, presentando resultados de índole teórico y analítico, para la solución del problema planteado. Los resultados presentan una mirada de la evaluación para el currículo por competencias, centrada en la importancia del proceso educativo, y no en el profesor o el estudiante, como se viene investigando actualmente, permitiendo así un proceso de enseñaza-aprendizaje más equilibrado. El resultado didáctico presenta una plantilla para facilitar la construcción de las preguntas propuestas en la taxonomía SOLO, junto al desarrollo del paso a paso de la metodología del círculo hermeneutico. En el estudio es importante la generación de estrategias de investigación, que puedan presentarse como la posibilidad de entender la filosofía y la pedagogía, como una vez Aristóteles y Platón las entendieron, como posibilidad de transformación y emancipación de lo humano. La discusion se centra en que los tipos de evaluación de orden cualitativo o cuantitativo por separado, no son suficientes para desarrollar mediciones fiables de los avances cognitivos en los estudiantes, la taxonomía SOLO, permite solamente generar una estrategia de aprendizaje vinculada a valoración de competencias propias del ejercicio de lo cognitivo.
\end{abstract}

Palabras clave: Educación; Enseñar; Aprender; Sujeto; Profundizar 


\begin{abstract}
The investigation examines the problem of evaluating through the competency model using Biggs theory, taking into account three fields of knowledge from a critical perspective, finally presenting a third, which shows the results of the investigation from the evaluative and interpretive configuration of the process. evaluative by competencies. After the above, the hermeneutical method is applied, using the Gademarian perspective, based on the adaptation proposed by (Noriega, 2018, 1-8), focused on the textual analysis from the educational perspective, through the three related fields of knowledge with the context, presenting results of a theoretical and analytical nature, for the solution of the problem posed. The results present a look at the evaluation for the competency curriculum, focused on the importance of the educational process, and not on the teacher or student, as is currently being investigated, allowing a more balanced teaching-learning process. The didactic result presents a template to facilitate the construction of the questions proposed in the SOLO taxonomy, together with the development of the methodology of the hermeneutic circle step by step. In the study it is important to generate research strategies, which can be presented as the possibility of understanding philosophy and pedagogy, as Aristotle and Plato once understood them, as a possibility of transformation and emancipation of the human. The discussion focuses on what the types of qualitative or quantitative evaluation separately, are not sufficient to develop reliable measurements of cognitive advances in students, the taxonomy ONLY, allows to generate a learning strategy linked to the assessment of competencies specific to the exercise of the cognitive.
\end{abstract}

Keywords: Education; Teaching; Learning; Subject; Deepen

\title{
1. INTRODUGGIÓN
}

En la investigación se analizan tres campos de conocimiento: pedagogía, relacionado con el aprendizaje. Filosofía; del mundo de la teoría, al mundo de la vida, y un tercer campo, didáctica, referido a la evaluación. Cada uno de estos apoyado por teóricos como John Locke, con su concepto sobre educación. Edmund Husserl, con su concepción sobre el mundo y sus relaciones. John Biggs, con el concepto de evaluación aplicada. Dijk, con el análisis del discurso, el texto y el contexto. Tyler Ralph con los principios básicos de la evaluación, y por último Hattie, y Brown con las técnicas evaluativas de la taxonomía SOLO.

Por otra parte se examina el aprendizaje como un acto mediado por los sentidos, que tiende a ser exteriorizado a través del ejercicio de la búsqueda del origen del conocimiento. Además de resaltar que quienes piensan la pedagogía, las didácticas y aún la evaluación, están actuando en el mundo de la teoría, para afectar el mundo de la vida, vehiculizando así la comunicación a través de los actos de habla. 
a) Metodología

Se efectúa una investigación hermenéutica aplicada a la interpretación del texto, empleando la técnica de análisis de contenido de documentos (Noriega, 2002. 1-8), buscando lograr el análisis formal, semántico y socio-cultural, a partir de la interpretación de los textos, aplicando para ello el círculo hermenéutico de Gadamer, junto a los diferentes elementos generadores de tres campos de conocimiento, en correlación con el entorno social, desde una visión crítica. A continuación, se presentan las etapas del método y su correspondiente aplicación.

b) Fases del método hermenéutico

Lo siguiente es aplicar la metodología de análisis textual siguiendo los pasos propuestos por Noriega, (2002).

\section{Fase 1. La compresión}

- Ideas fuerza

1. la educación es un todo comprensible y verificable. Comprensible por la pedagogía y verificable por la evaluación.

2. la evaluación por competencias, basada en la metodología SOLO de Biggs, permite vincular elementos propios del contexto y de las categorías, mundo teórico y mundo de la vida, al proceso de enseñanza-aprendizaje.

- Aplicación de la compresión

3. Elementos propios del análisis documental entorno a la evaluación de los aspectos cualitativos de las competencias y su relación con el contexto

Es importante describir como el enfoque de la investigación es trazado por la comprensión de que la técnica evaluativa de Biggs, solo permite evaluar elementos cualitativos de la competencia, y que a su vez dicha valoración, refleja solo un porcentaje de la adquisición de la misma por parte del estudiante. Todo esto enmarcado en un contexto socioeducativo apoyado por las investigaciones de Habermas, Locke, Dijk y Tyler Ralph, entre otros. A continuación, se presenta bajo el título de legitimación teórica el desarrollo de la aplicación de la comprensión, aspecto que hace parte de la fase 1 . 
Cuadro 1. Legitimación de la consistencia teórica.

\begin{tabular}{|c|c|c|}
\hline Tipos de textos & Bibliografía del texto & Localidades problemáticas \\
\hline Filosofía & $\begin{array}{l}\text { Habermas Jürgen. Teoría } \\
\text { de la acción comunicativa }\end{array}$ & $\begin{array}{l}\text { Localidad problémica } \\
\text { Campo 1: es el aprendizaje un acto mediado } \\
\text { por los sentidos, que tiende a ser exteriorizado a } \\
\text { través del ejercicio de la búsqueda del origen del } \\
\text { conocimiento. }\end{array}$ \\
\hline Locke John (2012) & Husserl Edmund. ID & \\
\hline $\begin{array}{l}\text { Pensamiento } \\
\text { sobre la } \\
\text { educación. }\end{array}$ & $\begin{array}{l}\text { E A S relativas a una } \\
\text { fenomenología pura y una } \\
\text { filosofía fenomenológica. }\end{array}$ & \\
\hline Pedagogía & $\begin{array}{l}\text { Biggs John. Calidad del } \\
\text { aprendizaje universitario. }\end{array}$ & $\begin{array}{l}\text { Localidad problémica campo } 2 \text { : El proceso de } \\
\text { enseñanza aprendizaje hace parte del mundo de } \\
\text { la vida y que quienes piensan la pedagogía, las } \\
\text { didácticas y la evaluación, están actuando más en } \\
\text { el mundo de la teoría. }\end{array}$ \\
\hline
\end{tabular}

\begin{tabular}{lll}
\hline & $\begin{array}{l}\text { Dijk. Texto y contexto, } \\
\text { semántica y pragmática del } \\
\text { discurso. }\end{array}$ & \\
\hline Didáctica & $\begin{array}{l}\text { Tyler Ralph. Principios } \\
\text { básicos del currículo. }\end{array}$ & $\begin{array}{l}\text { Localidad problémica campo 3: las técnicas de } \\
\text { evaluación generan procesos de maduración del } \\
\text { pensamiento desde las condiciones iniciales del } \\
\text { mismo, hasta un número infinito de posibilidades } \\
\text { en el aprendizaje y en la enseñanza. }\end{array}$ \\
\hline
\end{tabular}

John Hattie, Gavin T. L.

Brown. Assessment Tools

for Teaching and Learning

Technical

Fuente: Elaboración propia.

Fase 2. Interpretación general de las categorías.

- Aplicación de la interpetación

Enunciado hermenéutico 1. Es el aprendizaje un acto mediado por los sentidos, que tiende a ser exteriorizado a través del ejercicio de la búsqueda del origen del conocimiento y este proceso, se relaciona con la calidad educativa.

Enunciado hermenéutico 2. El proceso de enseñanza aprendizaje hace parte del mundo de la vida, y quienes piensan la pedagogía, las didácticas y aún la evaluación, actuán desde el mundo de la teoría, afectando así al mundo de la vida, por consiguiente los procesos de enseñanza aprendizaje de los estudiantes y por ende, al contexto relacionado con la cultura particular, en la que este inmerso el currículo.

Enunciado hermenéutico 3. Las técnicas de evaluación propician procesos de maduración del aprendizaje, en los estudiantes desde las condiciones iniciales del mismo, hasta generar un número infinito de posibilidades tanto en este, como en la enseñanza. 
Cuadro 2. Categorías interpretadas en elación al intérprete y al texto.

\begin{tabular}{|c|c|c|c|}
\hline Categorías & Aspiración del intérprete & Texto & $\begin{array}{l}\text { Lo ofrecido significativamente } \\
\text { por el texto }\end{array}$ \\
\hline $\begin{array}{l}\text { Proceso } \\
\text { comunicativo } \\
\text { Relacion 1: } \\
\text { comunicación } \\
\text { educacion. }\end{array}$ & $\begin{array}{l}\text { Encontrar algunos elementos } \\
\text { del proceso comunicativo- } \\
\text { educativo, que se relacionen } \\
\text { con la diada, profesor } \\
\text { estudiante. }\end{array}$ & $\begin{array}{l}\text { Habermas } \\
\text { Jürgen. Teoría } \\
\text { de la acción } \\
\text { comunicativa. }\end{array}$ & $\begin{array}{l}\text { El aspecto comunicativo } \\
\text { establece procesos arbitrarios } \\
\text { y convencionales en relación } \\
\text { con el mundo de la vida. }\end{array}$ \\
\hline $\begin{array}{l}\text { Profundidad en el } \\
\text { proceso educativo. } \\
\text { Relación 2: calidad } \\
\text { educativa en } \\
\text { relacion pensar la } \\
\text { educación. }\end{array}$ & $\begin{array}{l}\text { Establecer la relación entre } \\
\text { un enfoque a profundidad } \\
\text { de los procesos educativos y } \\
\text { su conexión con postulados } \\
\text { educativos pasados. }\end{array}$ & $\begin{array}{l}\text { Biggs John. } \\
\text { Calidad del } \\
\text { aprendizaje } \\
\text { universitario. } \\
\text { Locke John } \\
\text { Pensamiento } \\
\text { sobre la } \\
\text { educación. }\end{array}$ & $\begin{array}{l}\text { Un enfoque más profundo } \\
\text { en la educación, permite } \\
\text { el desarrollo de sistemas } \\
\text { educativos universitarios } \\
\text { más eficientes, permitiendo } \\
\text { subir el nivel de calidad, } \\
\text { Institucional. }\end{array}$ \\
\hline $\begin{array}{l}\text { Evaluación } \\
\text { Relación 3: } \\
\text { currículo, texto, } \\
\text { contexto y } \\
\text { discurso. }\end{array}$ & $\begin{array}{l}\text { Develar la importancia de un } \\
\text { tipo de evaluación de carácter } \\
\text { cualitativo y cuantitativo, } \\
\text { que permita mejorar el } \\
\text { aprendizaje. }\end{array}$ & $\begin{array}{l}\text { Tyler Ralph } \\
\text { Principios } \\
\text { básicos del } \\
\text { currículo. }\end{array}$ & $\begin{array}{l}\text { Relación evaluación, junto a } \\
\text { la educación y el aprendizaje, } \\
\text { son vehiculizados por el } \\
\text { currículo para obtener } \\
\text { mayores niveles de calidad, } \\
\text { basados en criterios cuanti- } \\
\text { cualitativos. }\end{array}$ \\
\hline Contexto-discurso & $\begin{array}{l}\text { Importancia del contexto y su } \\
\text { relación con el discurso en el } \\
\text { proceso de aprendizaje. }\end{array}$ & $\begin{array}{l}\text { Dijk. Texto } \\
\text { y contexto, } \\
\text { semántica y } \\
\text { pragmática del } \\
\text { discurso. }\end{array}$ & $\begin{array}{l}\text { La importancia del texto y } \\
\text { el contexto en relación al } \\
\text { discurso, es vehiculizada a } \\
\text { través de la lengua, siendo el } \\
\text { hablante el principal gestor } \\
\text { de discursos de calidad que } \\
\text { afectan su entorno. }\end{array}$ \\
\hline
\end{tabular}

Fuente: Elaboración propia.

Fase 3. Aplicación

Se hace el análisis a la 1 primera relación (Relacion 1: comunicación, mundo de la vida y educación) encontrada a través del círculo hermenéutico. Por considerarla el eje central de toda la investigación, además que resume la escencia de las demás relaciones encontradas. Ver cuadro análisis semántico.

1. Categorizar las relaciones encontradas en el círculo aplicado a los tres niveles de análisis. 
Cuadro 3. Categorías y las relaciones que surgen de estas, en correspondencia con el análisis formal.

\begin{tabular}{ll}
\hline Análisis formal & Elementos del análisis formal \\
\hline $\begin{array}{l}\text { Relacion 1: } \\
\text { comunicación, mundo } \\
\text { de la vida y educación. }\end{array}$ & $\begin{array}{l}\text { Textos: Texto 1. Pensamiento sobre la educación. Texto 2. Teoría de la acción } \\
\text { comunicativa. }\end{array}$ \\
& $\begin{array}{l}\text { Composición del texto: reflexiones de orden filosófico sobre el mundo de la } \\
\text { vida y la comunicación, aplicadas en contextos escolares. }\end{array}$ \\
& $\begin{array}{l}\text { Conexiones en el tiempo de lo narrado: reflexión sobre la educación del } \\
\text { pasado y la vida (Locke) vigente en la reflexión presente sobre el mundo de la } \\
\text { vida. (Habermas) } \\
\text { Lazos efectúales: }\end{array}$
\end{tabular}

3a persona singular, presente indicativo, en relación a cómo enseñar. Texto 1.

3 a persona singular, presente indicativo, en relación al mundo de la vida y a cómo comunicar. Texto 2.

Relación 2: calidad Textos: Texto 1: Calidad del aprendizaje universitario. Texto 2. Pensamientos educativa en relación a sobre la educación.

pensar la educación.

Composición del texto: reflexiones y teoría entorno a la importancia de la calidad educativa, junto a la reflexión del proceso de enseñanza aprendizaje.

Conexiones en el tiempo de lo narrado: reflexión sobre la educación del pasado y la vida (Locke) vigente en la reflexión presente la calidad educativa y los procesos de enseñanza. (Tyler)

Lazos efectúales:

3a persona singular, presente indicativo, en relación a la calidad educativa. Texto 1.

3a persona singular, presente indicativo, en relación a la vida y la manera de educar, con calidad. Texto 2 .

Relación 3: currículo, texto, contexto y discurso.
Textos: Texto 1: Principios básicos del currículo. Texto y contexto, semántica y pragmática del discurso.

Composición del texto: teoría que relaciona los principios iniciales de evaluación y didáctica aplicada, además del análisis del discurso aplicado al hablante.

Conexiones en el tiempo de lo narrado: la reflexión está en presente, la calidad educativa y los procesos de enseñanza. (Tyler) vigente en la reflexión sobre el texto, contexto y el discurso. (Dijk)

Lazos efectúales:

3a persona singular, presente indicativo, en relación la calidad educativa y los procesos de enseñanza. Texto 1.

3a persona singular, presente indicativo, el texto, contexto y el discurso.Texto 2.

Fuente: Elaboración propia. 
Cuadro 4. Análisis semántico en relacion al contexto de las categorías.

\begin{tabular}{|c|c|}
\hline Análisis semántico & Elementos del análisis semántico \\
\hline $\begin{array}{l}\text { Texto: Teoría de la acción comunicativa. } \\
\text { Párrafo 1: “El mundo sólo cobra objetividad por el } \\
\text { hecho de ser reconocido y considerado como uno y el } \\
\text { mismo mundo por una comunidad de sujetos capaces } \\
\text { de lenguaje y de acción. Párrafo 2: El concepto } \\
\text { abstracto del mundo es condición necesaria para que } \\
\text { los sujetos que actúan comunicativamente puedan } \\
\text { entenderse entre sí sobre lo que sucede en el mundo } \\
\text { o lo que hay que producir en el mundo. Párrafo } 3: \\
\text { Con esta práctica comunicativa se aseguran a la vez } \\
\text { del contexto común de sus vidas, del mundo de la } \\
\text { vida que intersubjetivamente comparten." (Habermas } \\
\text { 1999, pp. } 30,31)\end{array}$ & $\begin{array}{l}\text { Análisis de estructura superficial. elementos en la } \\
\text { narración: } \\
\text { lugares: el mundo. } \\
\text { tiempos: presente. } \\
\text { Objetos: lenguaje, mundo, práctica comunicativa. } \\
\text { Sujetos: sujetos. } \\
\text { Acciones: actuar, entender, producir, comunicar, } \\
\text { asegurar, compartir. } \\
\text { Situaciones: el mundo es conocido y reconsiderado } \\
\text { por algunos sujetos. } \\
\text { Concebir que es lo abstracto del mundo, asegurando } \\
\text { lo común entre estos y el contexto donde se vive y se } \\
\text { aprende. }\end{array}$ \\
\hline $\begin{array}{l}\text { Redes interconectivas entre la estructura superficial y } \\
\text { su estructura profunda } \\
\text { Red interconectiva 1: entre el párrafo } 1 \text { y } 2 \text {; mundo- } \\
\text { sujetos; sujetos- mundo reconocido y considerado; } \\
\text { comunidad de sujetos- lenguaje y acción: concepto } \\
\text { abstracto del mundo- actuación comunicativa de los } \\
\text { sujetos; mutuo entendimiento- susesos y producción } \\
\text { en el mundo. } \\
\text { Red interconectiva 2: entre el párrafo } 2 \text { y } 3 \text {; concepto } \\
\text { abstracto del mundo- actuación comunicativa de los } \\
\text { sujetos; mutuo entendimiento- susesos y producción } \\
\text { en el mundo: práctica comunicativa- contexto común; } \\
\text { mundo de la vida-relaciones intersubjetivas. }\end{array}$ & $\begin{array}{l}\text { Análisis de estructura profunda } \\
\text { Lexicón: } \\
\text { Categorías léxicas -o abiertas: corresponden a lo } \\
\text { señalado con letra kursiva. } \\
\text { Categorías funcionales -o cerradas: corresponden a } \\
\text { las palabras subrayadas. }\end{array}$ \\
\hline
\end{tabular}

\begin{tabular}{|c|}
\hline Análisis semántico \\
\hline $\begin{array}{l}\text { Texto: Pensamientos sobre la educación.. } \\
\text { Sección 1: "Como la mente del hombre es muy } \\
\text { estrecha y muy lenta en trabar conocimiento con las } \\
\text { cosas yadoptar las nuevas verdades, pues ningún } \\
\text { hombre sería capaz, ni en una vida mucho más } \\
\text { larga que la nuestra, de conocer todas las verdades, } \\
\text { Sección 2: es prudente que en nuestra búsqueda del } \\
\text { conocimiento empleemos nuestros pensamientos en } \\
\text { las cuestiones fundamentales yesenciales, evitando } \\
\text { cuidadosamente las insignificantes, Sección 3: sin } \\
\text { apartamos de nuestro propósito principal en favor de } \\
\text { lo meramente incidental." (Locke, 2012. 344) }\end{array}$ \\
\hline
\end{tabular}

Redes interconectivas entre la estructura superficial y su estructura profunda

Red interconectiva 1: entre la Sección 1 y 2; la mente del hombre en relación con el aprendizajede nuevas verdades: búsqueda del conocimientoempleo de los pensamientos en solamente lo escencial.

Red interconectiva 2: entre el Sección 2 y

3; búsqueda del conocimiento-empleo de los pensamientos en solamente lo escencial: enfocarse al propositi principal, sin distracciones.
Elementos del análisis semántico

Análisis de estructura superficial. elementos en la narración:

lugares: el mundo.

tiempos: presente.

Objetos: lenguaje, mundo, práctica comunicativa.

Sujetos: sujetos.

Acciones: actuar, entender, producir, comunicar, asegurar, compartir.

Situaciones: el mundo es conocido y reconsiderado por algunos sujetos.

Concebir que es lo abstracto del mundo-sujeto, asegurando lo común entre estos y el contexto donde se vive y se aprende.

Análisis de estructura profunda.

Lexicón:

Categorías léxicas -o abiertas: corresponden a las palabras señaladas con letra kursiva.

Categorías funcionales -o cerradas: corresponden a las palabras subrayadas.

Fuente: Elaboración propia. 
Cuadro 5. Contexto de las categorías: análisis socio-cultural.

Análisis socio-cultural Elementos del análisis socio-cultural

Texto: Teoría de la acción comunicativa.

Condiciones socioculturales donde se produjo el relato: se aumentan las tensiones por la guerra fría, USA sienta las bases del proyecto neoliberal para una economía mundial, de libre mercado.

Plataforma de dinámicas de pensamiento: inicia la concepción de la economía de libre mercado y con ello los procesos de intercambio académico a mayor escala.

La internet sigue avanzando y se inicia la integración a procesos comunicativos y académicos internacionales.

Marcos de organización sociocultural:

- Estilo de vida:. Sigue siendo tradicional, se imponen los efectos de la guerra fría y las comunidades virtuales, permiten intercambio cultural.

-Valores sociales: en desaroollo, de un tipo de sociedad más abierta conservando los valores tradionales, pero comunicándose de manera simultanea.

- Elementos demográficos: El siglo pasado (...) durante su transcurso la población (...) pasa de casi $\mathbf{1 . 6 0 0}$ millones a comienzos de siglo a más de 6000 millones al concluirlo. (Alcañiz, 2008, párr. 39)

Codificación de la realidad cultural comprendida e interpretada: la comunicación, desde el texto corresponde con los procesos comunicativos en contexto, relacionándolos con el mundo de la vida, y por ende con la educación, en función de un tipo de sociedad que es tranformada por el acto comunicativo, en relación con las normas arbitraria y convencionalmente consertadas.

Texto: Pensamientos sobre la educación.. Marcos de organización sociocultural:

Condiciones socioculturales donde se produjo el relato:

Plataforma de dinámicas de pensamiento: surge la nueva burguesia y un tipo de pensamiento reformista de la época.

La educación es pensada más desde los criterios éticos que morales, tanto protestantes como católicos interactuan en el socialmente.
Estilo de vida: tradicional centrado en el pensamiento católico y protestante.

Valores sociales: teocéntricos, centrados en la visión religiosa de la cultura judeocristiana. Elementos demográficos: en el siglo XVII, la poblacion era de $\mathbf{5 7 8}$ millones (Alcañiz, 2008, párr. 38)

Codificación de la realidad cultural comprendida e interpretada: la educación, desde el texto, se reflexiona en relación al rescate de la razón y a la modificación del contexto, en función de un tipo de formación centrada en los valores y en los principios de la ilustración, evidente a sus vez la imposibilidad de pensar las relación enseñanza aprendizaje sin afectar el ambiente y a quienes lo habitan.

Fuente: elaboración propia. 


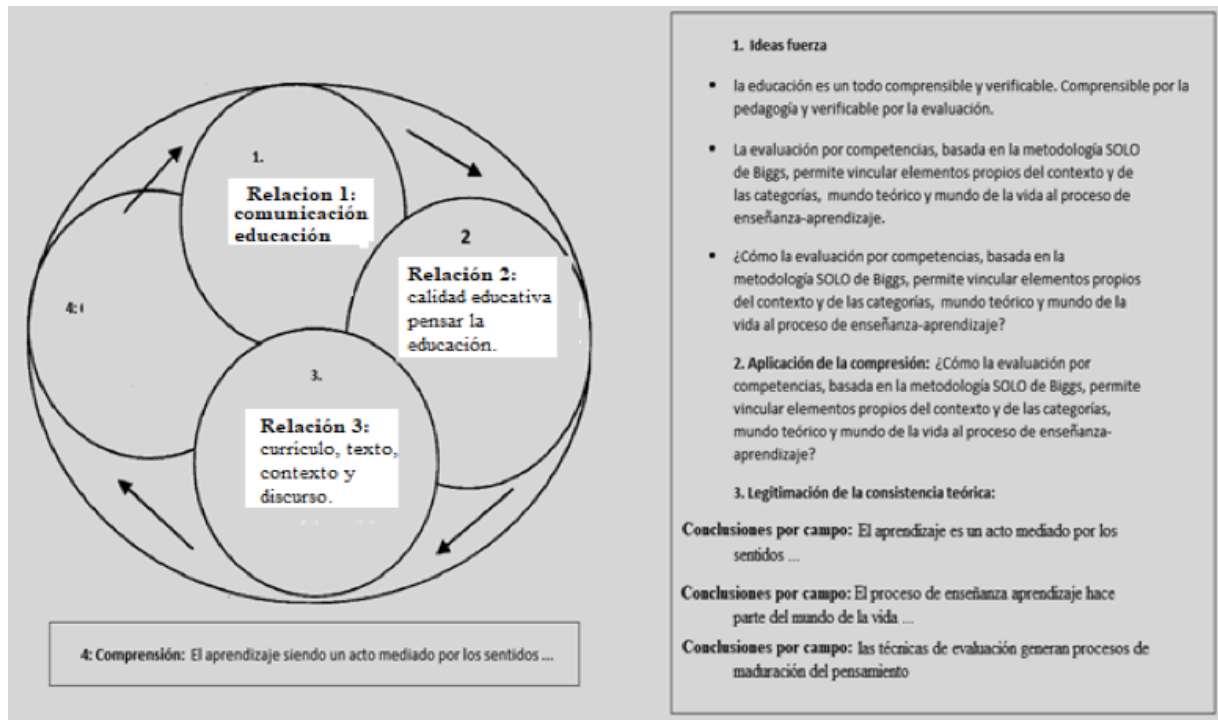

Figura 1. Círculo hermenéutico desarollado Fuente: Elaboración propia.

El último paso del análisis de contenidos, se representa en el poliedro, destacando la correspondencia permanente de los elementos del mismo, en relación a los resultados de la investigación y a la verificación de la hipótesis planteada.

\section{Fase de aplicación en la matriz poliédrica.}

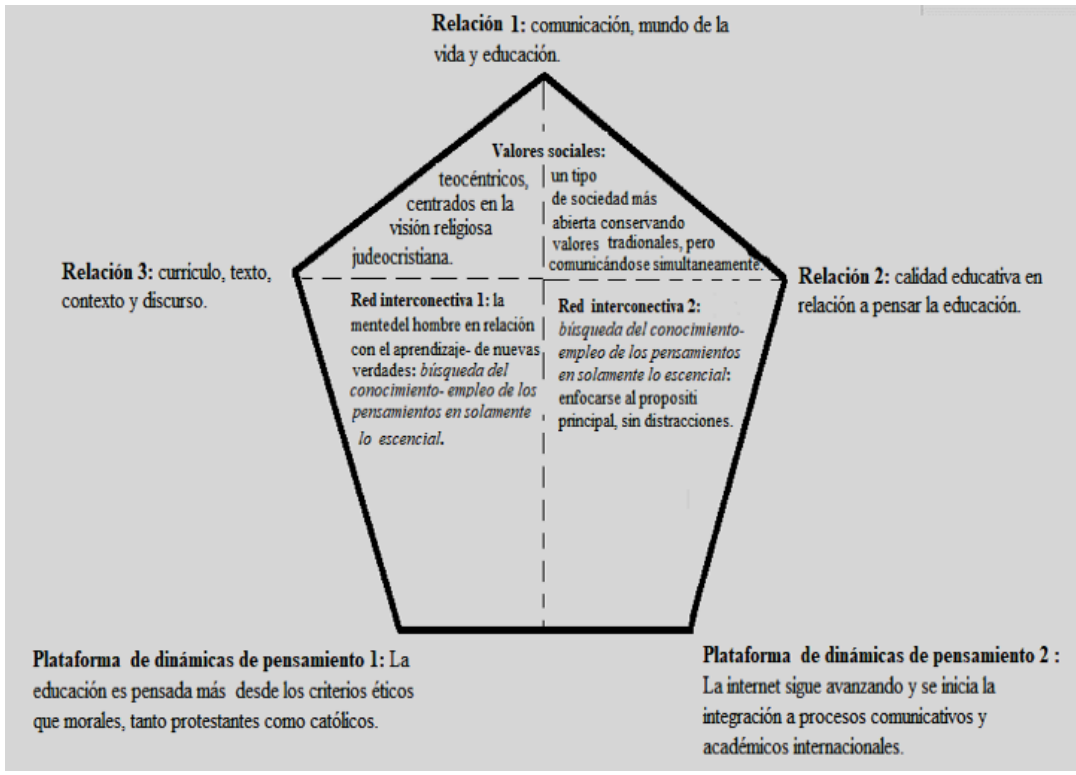

Figura 2. Matriz poliédrica categorías expresadas en relaciones entre los textos. Fuente: Elaboración propia. 


\section{GONTENIDO}

\subsection{El Mundo Evaluativo desde la Pedagogía}

Los continuos cambios, los nuevos horizontes dentro del contexto mundial en que debe sobrevivir la especia humana, obligan a adquirir nuevas posturas educativas, a innovar las estrategias didácticas, a preguntar sobre los problemas diarios que la práctica pedagógica plantea, buscando obtener respuestas enriquecedoras durante el quehacer educativo, permitiendo que los individuos tomen conciencia y se acoplen con el mundo que les rodea, logrando así discernir sobre los conflictos que les afectan.

Hoy más que nunca es una necesidad sentida la preparación de los jóvenes en forma integral, es decir, para el logro del adecuado desempeño en la actividad profesional y en su quehacer en sociedad.

Para completar el reto de la integración educativa, es necesario utilizar herramientas de avanzada, que permitan conocer el papel de la evaluación como pilar formativo del individuo. Teniendo encuenta que para lograr un cambio de fondo en la educación, se debe ejercer permanentemente la reflexión y la profundización en aspectos pedagógicos y evaluativos, propios del ámbito educativo.

Teniendo en cuenta lo anterior es necesario señalar que la educación de hoy, implica un análisis de las características de la evaluación, ya que tanto el estudiante como el profesor están en permanente confrontación entre el mundo académico y el mundo productivo, no obstante, se debe dar un giro acorde al sistema educativo actual, a la luz de los nuevos paradigmas en adopción; esto implica un profesor que cree mecanismos pedagógicos acordes a la llegada del discurso de competencias a la vida escolar, en todos los niveles.

Se debe tener en cuenta también que en la educación de hoy existen aspectos que han migrado de otras disciplinas al currículo, siendo estos:

- la lectura y la escritura son actividades complementarias y no fundamentales, para la educación.

- los grupos numerosos alteran y dificultan el proceso de enseñanza-aprendizaje, puesto que la competencia debe adquirirse en forma individual y corresponde a un mismo patrón de aplicación.

- es necesario fortalecer los cursos en función de las competencias.

El nuevo paradigma educativo de las competencias es un reto gigantesco sobre todo para el docente que debe comprenderlo, comprometerse con sus principios y aplicarlo en el aula de clase, teniendo encuenta que el discurso de las competencias tiene un origen linguístico y administrativo, siendo que las competencias provienen del mundo de la economía, donde se debe evidenciar en poco tiempo la eficiencia y la eficacia en los procesos productivos. 
La educación por otra parte es un proceso verificable a largo plazo, y los estudiantes no son productos homogéneos salidos de una máquina, es por ello fundamental, recordar que educar sigue siendo el sembrar semillas que deben generar con el transcurrir del tiempo, un hombre nuevo, propiciador de la paz, de la no-violencia y del desarrollo sotenible.

Es por esto que para poder responder al nuevo reto, la evaluación educativa tiene que aplicar sistemas matemáticos precisos, que permitan establecer tablas de eficiencia, eficacia y demostraciones relacionadas con la adquisición de habilidades. Sin dejar de lado el componente cualitativo de las mismas.

La llegada de las competencias al sistema educativo, sin preparación previa, ni procesos reflexivos tiende a desvirtuar en ocasiones su objetivo último: la formación de seres integrales, por ende, la evaluación tiende a convertirse en cantidades que pocos saben descifrar, propiciando la frustración académica en el educando, y en general, afectando negativamente al sistema educativo.

En la contemporaneidad educativa, se hace necesario resaltar que si bien el desarrollo tanto científico como tecnológico, generan nuevos conocimientos en las diferentes áreas del saber, también lo es que el desconocimiento de las bases construidas por generaciones de pedagogos, filósofos y científicos sobre cualquier tema que corresponda al saber, no solamente es un acto desprovisto de la mayor sensatez, sino también constituye un limitante para el avance del conocimiento especialmente científico. Desde esta lógica es importante referir la concepción de enseñanza que aporta John Locke.

\subsection{Campo 1. Pedagogía: sobre el aprendizaje.}

"Como la mente del hombre es muy estrecha, y muy lenta en trabar conocimiento con las cosas y adoptar las nuevas verdades, pues ningún hombre sería capaz, ni en una vida mucho más larga que la nuestra, de conocer todas las verdades, es prudente que en nuestra búsqueda del conocimiento empleemos nuestros pensamientos en las cuestiones fundamentales y esenciales, evitando cuidadosamente las insignificantes, sin apartamos de nuestro propósito principal en favor de lo meramente incidental." (Locke, 2012. 344)

Aquí Locke refiere una consideración pragmática, al centrar los procesos de aprendizaje en elementos significativos, más no banales, aspecto este que permite centrar los procesos de atención en relación a cuestiones específicas, en función de objetivos precisos, tanto para el aprendizaje como para la enseñanza, entendiéndose que el profesor realiza constantemente el ejercicio del aprendiz y del maestro, en función del logro del aprendizaje de sus estudiantes. Esta precisión a la cual se alude, tiene que ver también con procesos de planeación no incidentales, al contrario, como ocurre en la mayoría de los ambientes educativos actuales, que no piensan de manera 
relacional tanto el currículo, la evaluación y las didácticas, todas estas vistas como un todo común que tiene relación permanente con la enseñanza y el aprendizaje. La herencia de la manera de razonar de la ciencia del siglo XIX y XX, se evidencia en este tipo de pensamiento que imposibilita ver las relaciones generales entre los distintos elementos del todo, impidiendo la generación de verdadero pensamiento crítico, que, a su vez, nubla la posibilidad de desarrollar habilidades relacionales entre los distintos conocimientos del corpus científico escogido.

Aquí aparece la concepción actual del olvido de lo clásico, ya antes mencionada, que se evidencia en el concepto de modernidad líquida, sostenida como principio de pensamiento social y filosófico en el siglo XXI.

"Esta modernidad se vuelve "líquida" en el transcurso de una "modernización" obsesiva y compulsiva que se propulsa e intensifica a sí misma, como resultado de la cual, a la manera del líquido — de ahí la elección del término-, ninguna de las etapas consecutivas de la vida social puede mantener su forma durante un tiempo prolongado." (Bauman, 2013, p.17)

Es clara la postura de Bauman cuando señala que este tipo de sociedad no puede mantener su forma durante tiempo prolongado, y que existe una tendencia compulsiva u obsesiva en las diferentes expresiones de lo social, aspecto al cual no pueden sustraerse las disciplinas del saber, que se evidencian en las formas de conocimiento científico y los formalismos que esto suscita a nivel de las instituciones.

Siguiendo la premisa sobre el aprendizaje, es importante resaltar que el contexto en el que se aprende hoy esta mediatizado por un tipo de pensamiento líquido que impide centrarse en las cuestiones importantes de la educación, generando un activismo desmedido que hace lo contrario de lo recomendado por Locke, precisa lo accesorio dejando de lado lo esencial, en un caos indiferenciado y reduccionista que sólo busca el resultado sin la reflexión, valoración y transformación de los ambientes culturales, incluido en esta categoría a la educación. Ejemplo de ello es pensar la educación desde la perspectiva solamente del indicador, pero no evaluar si dicho indicador genera procesos de aprendizaje necesarios para asegurar la calidad educativa, en función de la exigencia, olvidando a priori los principios básicos del aprendizaje clásico y moderno. Pensar así sólo permite certificar externamente la educación, pero esto no asegura la calidad educativa a razón del olvido de los roles y la delimitación de las actuaciones de cada uno de los miembros de la escuela, siendo este el núcleo esencial de la institucionalidad del saber científico, filosófico, estético o teológico.

La segunda consideración de Locke, se refiere a la capacidad de ver más allá de las cuestiones simples con carácter denotativo e inquirir sobre aspectos más complejos y profundos a saber.

"Hemos de acostumbrarnos, en cualquier cuestión propuesta, a examinar y encontrar lo que tiene en el fondo. La mayor parte de las dificultades con que nos encontramos, 
si las consideramos bien y rastreamos sus orígenes, nos conducen a alguna proposición que, sabiendo que es cierta, aclara la duda y da una solución fácil a la cuestión (...).” (Locke, 2012, p. 345)

Esta condición superficial de la sociedad líquida se opone a la olvidada estrategia del investigador educativo, que debe realizar procesos de análisis, síntesis y abstracción relacional y no relacional, permitiendo llegar a fondo en las cuestiones de la educación. Ir al origen es descender a lo oscuro del conocimiento, acceder a aquello que ha sido velado ya sea por la intención de unos pocos o por la excesiva dinámica de incorporar la novedad, olvidando las bases del mismo. Así pues, sigue siendo válido acudir a las fuentes del conocimiento que permitan desarrollar nuevas formas de este, a partir del origen de acontecimientos, conceptos, constructos, palabras y demás aspectos de la realidad teórica.

Este argumento es validado siglos después por John Biggs en su obra Calidad del aprendizaje universitario:

"El aspecto común más básico es que el significa no se impone ni se transmite mediante la enseñanza directa, sino que se crea mediante las actividades de aprendizaje de los estudiantes; es decir, sus enfoques del aprendizaje. El bajo nivel cognitivo de compromiso que se deriva del enfoque superficial da unos resultados fragmentarios que no transmiten el significado pretendido, mientras que es más probable que un enfoque más profundo ayude al estudiante a construir el significado. En consecuencia, hay que desaconsejar un enfoque superficial y estimular, en cambio, un enfoque profundo, que es la definición de trabajo de la buena enseñanza (...) p. 31 .

Mientras que Locke, habla de ver el fondo e ir al origen, Biggs refiere que es importante que el estudiante logre un enfoque más profundo, generándose mayor aprendizaje en relación a una mejor enseñanza. Ambos autores apuntan a desarrollar la enseñanza y el aprendizaje desde la perspectiva de profundización, a partir de estructuras cognitivas que connoten, generando procesos de adquisición del conocimiento rigurosos y de alto nivel.

El otro aspecto relacionado por el filósofo tiene que ver con la enseñanza natural del idioma, que sigue siendo válido para la enseñanza de las lenguas extranjeras.

"Cuando el niño sepa hablar es el momento de comenzar a enseñarle a leer. Pero sobre este punto dejadme repetir aquí lo que se está demasiado dispuesto a olvidar: es preciso tener cuidado de que la lectura no se convierta en un trabajo por sí misma y que el niño no la considere una tarea. Amamos, naturalmente; la libertad, como ya he dicho, y esto desde la cuna. Hay una gran cantidad de cosas que nos inspiran aversión sólo porque nos han sido impuestas." (Locke, 2012, p. 208)

A propósito de lo anterior, es importante resaltar, que el aprender debe convertirse en un espacio tan agradable como el juego, y que son definitivas las condiciones psicoeducativas en el aprendizaje. 
"Cuando sepa leer el niño bien el inglés, es tiempo de que aprenda a escribir" (Locke, 2012, p. 208)

Esta proposición del filósofo esclarece el principio del aprendizaje natural, es lógico que cualquier tipo de lengua debe ser enseñada teniendo en cuenta el orden natural de adquisición de la competencia, es decir, si enseño inglés como segunda lengua desde la gramática y desconozco como aprende el estudiante, cuáles son sus fortalezas, además de sus limitaciones al momento de aprender, y si a lo anterior le sumo el desconocimiento total de la manera en el que profesor aprende, genero un tipo de anomia educativa que sólo puede resolverse por medio de la imposición de la norma, perpetuándose así un tipo de educación tradicional, memorística y sin el sentido que debería tener para la adquisición de las competencias del estudiante. Por ende, el estudiante sólo es competente cuando aprende como aprende y siendo consciente de esto lo aplica para generar nuevo conocimiento, adquiriendo progresivamente la capacidad relacional, crítica y abstracta, partiendo si se quiere de los niveles uniestructural y multiestructural, como elementos primigenios de tipos de pensamiento más avanzados.

Siguiendo con el ejemplo, si enseño inglés -como segunda lengua- debo empezar con un aprendizaje basado en la oralidad, luego enseñaría a leer, enseguida de logradas ambas competencias, enseñaría lo gramatical que es el proceso de llevar a la conciencia mental, las normas, siendo trasversalizado-este tipo de conocimientode manera progresiva, ya que la escritura al ser la tecnología del entendimiento y al tener un carácter arbitrario, convencional, simbólico y abstracto, tiende a ser adquirida de manera más lenta.

\subsection{Campo 2. Filosofía: del mundo de la teoría al mundo de la vida.}

Siguiendo la cuestión anterior, con respecto al aprendizaje, se hace necesario generar reflexión en torno a una cuestión que ha sido tratada consciente o inconscientemente por diferentes filósofos, científicos y pedagogos, bajo el interrogante de ¿Cómo pasar del mundo de la teoría al mundo de la vida, en el proceso de enseñanza-aprendizaje?, entendiéndose este -el mundo de la teoríacomo el conjunto de teorías que forman el corpus teórico de la ciencia. Para ello entonces, es necesario explorar ambos conceptos a la luz de la teoría existente.

El mundo de la vida es una categoría explicada en cierta medida por Husserl, como bien lo refiere Herrera a continuación.

“Al final de su vida (1937) Husserl dio a conocer cómo en 1898 tuvo la intuición de que existe una correlación hombre-mundo; y que sólo en esos momentos había logrado él mismo dar pasos definitivos en la aclaración de dicha correlación, gracias al descubrimiento del significado del mundo de la vida.” (Herrera, 2010, p. 247) 
Esa correlación hombre-mundo es el tránsito entre lo que piensa y actúa el hombre en un contexto específico, junto a las relaciones que acontecen entre ambas partes para generar coherencia entre lo que se piensa y lo que se actúa en un contexto real. Husserl, descubre entonces como se inicia el trasegar entre ambos extremos frente a la manera en que el hombre se asume en el contexto, a partir de lo que piensa, dice y actúa.

“(...) El testimonio de Heidegger tiene una gran importancia, pues nos permite pensar que la concepción heidegeriana del hombre y del mundo pudo ser inspirada por los inéditos en los cuales Husserl daba sus primeros pasos en la formulación del mundo de la vida como camino de solución a la correlación hombre-mundo. La concepción heidegeriana según la cual la estructura fundamental del hombre es el «estar-en-elmundo» (in-der-Welt-sein) implica que hombre y mundo forman un «todo articulado», lo que significa una relación de co-pertenencia esencial, la presencia de cada uno de ellos implica la co-presencia del otro.” (Herrera, 2010, p. 248)

Esta correlación a la cual alude Heidegger, significa que el hombre que genera teorías sobre su percepción de la realidad, forma a su vez relaciones de codependencia entre él y el mundo -realidad o realidades- que interpreta y reflexiona a través de la teoría; desde esta perspectiva el argumento se podría referir al mundo de la teoría y al tránsito que existe entre este y el mundo de la vida, que después reflexionaría a profundidad Habermas, refiriéndose a los tres niveles del mundo de la vida. Queda claro que la premisa tiene un fundamento filosófico en relación a estos teóricos. Pero es más interesante, el todo articulado mencionado por la concepción Heidegeriana del «estar-en-el-mundo», que connota un mundo de relaciones generales y específicas articuladas para formar la dimensión relacional entre el hombre y el mundo. La figura 1 muestra gráficamente dichas correlaciones.

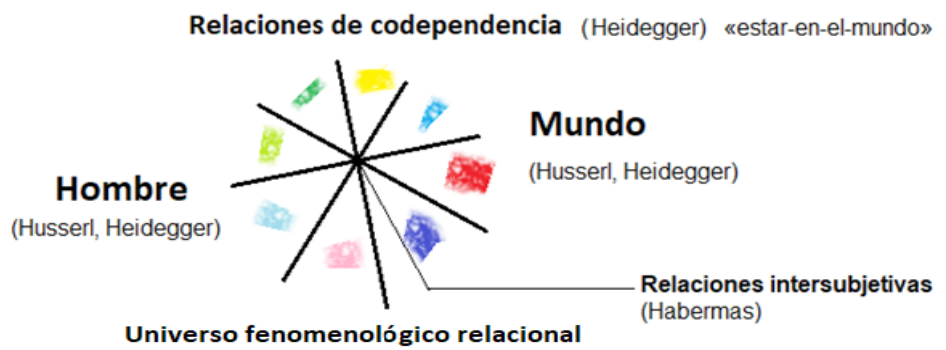

Figura 3. Relaciones de codependencia entre el hombre y el mundo.

Fuente: elaboración propia.

A continuación, se muestra la concepción de Husserl sobre el mundo, como se presenta en su obra IDEAS relativas a una fenomenología pura y una filosofía fenomenológica: 
“(...) Lo actualmente percibido, lo más o menos claramente copresente y determinado (determinado hasta cierto punto, al menos), está en parte cruzado, en parte rodeado por un horizonte oscuramente consciente de realidad indeterminada. Puedo lanzar hacia él rasgos de la mirada iluminadora de la atención, con variable resultado. Representaciones primero oscuras, pero que se van avivando, acaban por destacar algo determinado, eslabonándose una cadena de semejantes representaciones; el círculo de lo determinado se ensancha más y más, y en casos tanto, que queda establecida la conexión con el campo de percepción actual, como contorno central. Pero en general es distinto el resultado: una niebla vacía, de oscura indeterminación, se puebla de intuitivas posibilidades o presuntividades, y sólo se diseña la "forma" del mundo justamente en cuanto "mundo". El contorno indeterminado es, por lo demás, infinito. El nebuloso horizonte, nunca plenamente determinable, está necesariamente ahí.” (Husserl 1999, p.65)

He aquí que para el filósofo existe una medición intersubjetiva entre el hombre y el mundo que se explicita, cuando refiere la existencia de un entorno indeterminado, que hace parte de la percepción humana sobre el mundo y que viene a ser la percepción misma del contexto, a partir de la mediación de lo intuitivo, aspecto que Habermas tratará bajo el concepto de lo intersubjetivo, décadas después.

Existe entonces una relación permanente entre el mundo de la teoría pensado por el hombre, las realidades que le corresponden, y el mundo de la vida, que tiene permanente injerencia en la cotidianidad, siendo existente per se en relación al mundo de la teoría, es decir, el hombre que está sujeto a la muerte al igual que sus teorías sobre la realidad, depende necesariamente del mundo de la vida, pero no pasa lo contrario, ya que la vida misma continua si este hombre muere. Las relaciones entonces se abren a un universo relacional finito, pero ampliado de acuerdo al tiempo histórico vivido y al nivel de conocimiento de la realidad que se tenga en la época. El universo relacional entonces se redefine de acuerdo al nivel de avance científico, filosófico y estético, en función de la experiencia vivida por el colectivo, en relación también al nivel de conocimiento de la realidad cultural, y desde luego a los avances logrados en el mundo de la teoría.

Analícese ahora la concepción de Habermas sobre el mundo de la vida y sus tres niveles.

"El mundo sólo cobra objetividad por el hecho de ser reconocido y considerado como uno y el mismo mundo por una comunidad de sujetos capaces de lenguaje y de acción. El concepto abstracto de mundo es condición necesaria para que los sujetos que actúan comunicativamente puedan entenderse entre sí sobre lo que sucede en el mundo o lo que hay que producir en el mundo. Con esta práctica comunicativa se aseguran a la vez del contexto común de sus vidas, del mundo de la vida que intersubjetivamente comparten." (Habermas 1999, pp. 30,31)

Ya Habermas en las últimas 2 líneas de la cita anterior, lo deja claro, la relación entre el mundo de la vida y el sujeto -para Husserl, el hombre- es intersubjetiva 
y existe en cuanto es reconocido y considerado por una comunidad. El contexto entonces es vital a la hora de identificar los elementos que constituyen las relaciones entre el mundo de la vida y el mundo de la teoría, expresadas en lo que se podría denominar como el universo fenomenológico relacional. Siendo que estas relaciones de carácter intersubjetivo, están sometidas a las condiciones externas del contexto que Dijk retomará en su teoría.

El contexto es muy importante en las relaciones que se establecen, ya que se generan tensiones y distensiones en la dinámica del universo fenomenológico relacional y en el mundo de la vida.

La primera cuestión ya tratada en líneas anteriores exige una nueva consideración, recordemos que el mundo de la teoría según se dijo, parte del proceso reflexivo del hombre sobre el mundo -contexto- Dijk confirma lo anterior, al describir como las formas abstractas de las expresiones tienen relación con el significado, referidas en formas de comunicación:

"No hay ninguna razón a priori por la que una gramática no pudiera ser un SISTEMA FORMAL-SIGNIFICATIVOACTUATIVO DE REGLAS, en el que las formas abstractas de las expresiones se relacionasen tanto con significado como con la función de estas formas en contextos teóricamente reconstruidos de comunicación." (Dijk, 1980, p. 31)

El mundo de la vida y el de la teoría, encuentran su permanencia en el discurso y en todas las formas de comunicación, especialmente en aquellas relacionadas con la filosofía, la educación, la ciencia, la estética y la literatura, que tienen delimitado el corpussemántico, sintácticoypragmáticoenfuncióndeunobjetivoclaramentedefinido.

"La noción de PUNTO DE VISTA en relación con la cual hay que determinar la semejanza de los mundos y hechos, no sólo tiene propiedades semánticas, sino también PRAGMÁTICAS. Las frases están conectadas (o no) PARA algún hablante u oyente en un contexto particular de comunicación. Lo que está conectado para ciertos participantes de habla en algún contexto puede perfectamente estar desconectado para otros participantes." (...) (Dijk, 1980, p. 31)

Los factores condicionantes relacionados con el nivel de interpretación del hablante, referidos por Dijk, expresan una de las primeras relaciones de sentido, pudiendo ser nombrada como una relación lingüística contextual condicionada, referida a los factores socioculturales que se dan en las relaciones discursivas generadas a través de los actos de habla, es decir, el discurso no sólo es mediado por los elementos sociales que competen al hablante, sino también se recontextualiza a sí mismo, en función del acto pragmático ejecutado por este.

"Este mundo real será a menudo idéntico a aquél del que forma parte el contexto real, o bien cualquier otro mundo tomado como «punto de vista»." (Dijk, 1980, p.115) 
El texto anterior, muestra con claridad la relación entre el mundo real -para Husserl, Heidegger y Habermas el mundo de la vida- el contexto y necesariamente el discurso; que como se dijo anteriormente los contiene a todos, logrando transferirlos a través del acto comunicativo.

\subsection{Resultados}

\subsubsection{Campo 3. Didáctica: una mirada de la evaluación, para el currículo por competencias.}

La escuela de hoy requiere generar cambios a nivel no sólo estructural sino también profundo en una dinámica permanente de transformación curricular, que asume la competencia como posibilidad y como potencia, como posibilidad inserta a los diferentes actores del proceso de enseñanza y aprendizaje, en un tipo de diseño curricular que implica el saber hacer en contexto, bajo premisas precisas, como ocurre en el caso específico de la evaluación.

"En la educación basada en competencias, la elaboración del currículo acentúa el rol que debe desempeñar el docente en los tres ámbitos básicos de su perfil como guías del proceso de enseñanza, que son: la dimensión ético-valórica, la cual considera los principios de ciudadanía y convivencia humana; la académica, que incluye los conocimientos sobre la disciplina y la capacidad para investigar y generar conocimiento; y la profesional, en la que aporta su experiencia competitiva para transmitirla como ejemplo de superación y logro (...).” (Vargas, 1980, pp.10,11)

Aunque el darle relevancia al rol del profesor es importante para mejorar los procesos educativos, también lo es la relación que se establece entre el sujeto que aprende y quien enseña, siendo precioso resaltar esto, en la relación, y no sólo en el rol específico que cumplen los diferentes actores del proceso educativo. El desconocer que existe un universo fenomenológico de carácter relacional entre estos dos actores del acto educativo y el contexto que actúa como catalizador de este, ya sea de manera positiva o negativa, no permite ver la realidad de un currículo pertinente a la hora de aplicar tanto las didácticas propias de las disciplinas, como los procesos de evaluación que dependen de estas, o no, según fuere el caso. A partir de lo anterior es importante definir como se entiende la competencia en este contexto específico.

"Aquí la competencia es la armonía de lo lógico, lo ético y lo estético, es el movimiento armónico de los conocimientos, las actitudes y las habilidades. En ese sentido, este modelo busca seres competentes, no competidores. El competidor es contendor, el competente es solidario. (Unigarro, 2017, p.12)

Unigarro aporta claridad en cuanto define a la competencia desde la perspectiva de lo humano, lo que esta implica y significa al interior del aula de clase.

Dejando atrás la discusión sobre el currículo, es importante para los propósitos de la investigación centrarse en la evaluación, como elemento de enfoque. Para ello 
se hará una excepción a la regla de las relaciones hasta ahora tratadas, enfocando los esfuerzos en trabajar a partir del tema. Empecemos por la historia y el concepto de evaluación:

"El interés por la evaluación se remonta a mucho tiempo atrás. Forrest (citado en Sacristán, 2002) sitúa su primera manifestación histórica en el siglo II (a.C.), tratándose de una práctica china para seleccionar funcionarios. Se trata de las primeras prácticas selectivas de evaluación oral. Lemus (2012) añade que, algo así como un cuestionario de evaluación que utilizaron Sócrates y otros maestros de la época en sus prácticas de enseñanza, alrededor del siglo $\mathrm{V}$ (a.C.). Sitúa los sistemas de evaluación educativa (dogmáticos), entre los siglos V y XV (d.C.)" (Mora, 2015, p.12)

Este tipo de sistemas educativos, centraron la evaluación en procesos de selección para así evidenciar el desempeño netamente cuantitativo de un asunto, o del desempeño en una determinada profesión, no existía en ese entonces la evaluación pensada con fines expresamente educativos, hasta que los griegos generan un desarrollo insipiente del cuestionario e invitan a incluir la razón en la enseñanza; a través de las siguientes épocas se desconocen algunos principios griegos centrándose la educación, en el nivel de memorización y en la aplicación de normas sociales y estéticas, como bien lo presentan Chacón y Covarrubias, (2012). A continuación.

"Según Platón la ciencia no reside en la sensación, sino en el razonamiento sobre las sensaciones. Trasladado al campo de la pedagogía y de la educación, esto implica que el conocimiento generado por la memoria y por la imaginación, requiere elevarse al plano de la razón para llegar a la esencia de los objetos, lo cual solo se alcanza con el pensamiento y el entendimiento, ascendiendo dialécticamente de lo simple a lo inteligible" (Chacón y Covarrubias, 2012, p.146)

León hace una descripción objetiva sobre lo que fue la educación en Roma:

"Tras esta breve introducción en el conocimiento de la vida pública, que normalmente duraba un año, el joven romano pasaba a realizar su servicio militar, el tirocinium militiae; primero, como soldado raso; pero muy pronto, en correspondencia con el status social de la familia a la que pertenecía, se integraba, bien mediante elección del pueblo o por designación del jefe del ejército, entre los tribuni militum, es decir, la oficialidad de las legiones." (León, 2013, p. 474)

Este modelo educativo centrado en la milicia, la patria y la política, determina un tipo de evaluación tradicional centrada en el aprendizaje de las artes militares y políticas, es decir, en la memoria y el desempeño oral.

"En la Edad Media, el clero tiene como labor fundamental transmitir la cultura, siendo los monasterios los principales lugares para ello, surgen las primeras universidades. En esa época reina la metafísica; con el positivismo inicia la relación de la cuantificación, en la ciencia; observar, medir, verificar, la importancia que se genera a los modelos 
Evaluación por competencias en campos de conocimiento... - J. Jairo Mosquera

matemáticos para buscar la verificación, menciona Augusto Comte (1965) (...)” (Monzón, 2015, p. 13)

Es claro entonces que el elemento cuantitativo esta directa y proporcionalmente asociado al proceso evaluativo en la escuela tradicional.

"Los monjes redactan e iluminan códices en el scriptorium, leen libros en la biblioteca e imparten enseñanza gramatical y teológica en la escuela, donde acuden jóvenes que desean aleccionarse en el oficio religioso.” (Villa, 2017, p. 65)

Luego del reconocimiento histórico de las diferentes concepciones de evaluación en la cultura, es necesario realizar el análisis de la forma en que es aplicada en contextos educativos particulares.

"La evaluación se puede entender de diversas maneras, dependiendo de las necesidades, propósitos u objetivos de la institución educativa, tales como: el control y la medición, el enjuiciamiento de la validez del objetivo, la rendición de cuentas, por citar algunos propósitos. Desde esta perspectiva se puede determinar en qué situaciones educativas es pertinente realizar una valoración, una medición o la combinación de ambas concepciones." (Mora, 2004, p. 2)

Esta primera concepción de lo que es evaluación se refiere a los propósitos implícitos en el proceso evaluativo, privilegiando propósitos y objetivos, basados para su medición en criterios tanto cualitativos como cuantitativos.

Una segunda concepción sobre evaluación, está mediada por el enfoque formativo y genera un tipo de estrategia que incluye directamente a los estudiantes, en el proceso de enseñanza- aprendizaje.

"El docente que evalúa con base en el enfoque formativo debe definir y compartir con sus alumnos los criterios de evaluación que utilizará, por lo que se espera que antes de iniciar y durante una actividad, secuencia didáctica o proyecto, les comunique: los propósitos; lo que se espera que logren al final de la actividad (los aprendizajes esperados); el tipo de actividades que se planificarán; el tiempo destinado para su realización (...).” (Pardo Salazar y otros, 2013, p. 38)

La tercera concepción centrada en las competencias, hace más explícita la necesidad de evaluar desde un tipo de perspectiva basada en la razón y apoyada por indicadores.

"En un sistema de evaluación por competencias, los evaluadores hacen valoraciones según las evidencias obtenidas de diversas actividades de aprendizaje, que definen si un estudiante alcanza o no los requisitos recogidos por un conjunto de indicadores, en un determinado grado". (McDonald y otros, 2000, p. 42).

Por último, está la quinta concepción de la evaluación, que indica, la perspectiva del proceso educativo. 
"La evaluación y formación por competencias no pueden obedecer a estrategias que impliquen acciones de tipo interpretativo-estandarizado y conductistas, es decir, no es a partir de pruebas estándares, exámenes escritos o ejemplos copiados en forma directa de los textos, como se pretende vincular la realidad con los procesos de formación." (Bastidas, 2014, p.78)

Aunque el término formación que utiliza Bastidas, dista mucho del trabajo realizado en un currículo por competencias, si es importante destacar la alusión a que las estrategias de origen conductista no deben ser el centro del proceso evaluativo, ya que adquirir una competencia implica saber hacer en contexto.

El contexto en el cual se desarrolla este tipo de evaluación tiene que ver con la dinámica impuesta a través del siglo XXI, por el desarrollo tecnológico aplicado a la educación. Es necesario considerar este aspecto en relación a las posibilidades que tiene para mejorar los procesos de evaluación, bajo la base de las TICS. Veamos la propuesta de Lizcaino y Álvarez et al., (2017) apropósito del video como estrategia evaluativa.

"Dentro de estos recursos se encuentra el video, el cual se considera como un recurso motivante para los alumnos, es una manera moderna de aprender, facilita la comprensión y muestra ejemplos de los temas tratados durante las clases." (Lizcaino, Álvarez et al., 2017, p. 40)

Las nuevas maneras de evaluar corresponden a las nuevas formas en que se expresa el estudiante en un momento histórico particular. La evaluación en una hoja de papel, da paso en el siglo XX, a estrategias mediales como el video, que corresponden a la mentalidad audiovisual de la época.

Tyler tiene muy claro que el ejercicio de la evaluación permite no sólo la medición de los conocimientos, sino también supone una valoración objetiva de las experiencias del aprendizaje que tiene el estudiante.

"Resulta claro, pues, que la evaluación tiene por objeto descubrir hasta qué punto las experiencias de aprendizaje, tales como se las proyectó, producen realmente los resultados apetecidos; por lo tanto, supone determinar tanto los aciertos como los defectos de los planes." (Tyler, 1973, p. 108)

Más adelante refiere un aspecto importante que señala el contexto educativo y los diferentes elementos que están alrededor del proceso de aprendizaje.

"Finalmente, la enseñanza real supone muchísimas variantes, representadas por las diferencias individuales entre los estudiantes, los ambientes donde se desarrolla la enseñanza, la capacidad del docente para desarrollar los planes prefijados, su propia personalidad, y demás." (Tyler, 1973, p. 108)

Además de lo anterior, señala como las características personales del docente y su competencia profesional, permiten propiciar orden en los procesos didácticos, 
generándose consecuentemente un tipo de aprendizaje ordenado y ajustado a procesos de planeación, coherente con las necesidades del contexto educativo.

"It is noted that most secondary students in NZ schools take a surface approach to understanding both how and what they should learn (Brown, 2002a); whereas their teachers claim that the goal of their teaching is enhancing deep learning (Brown, 2002b). Brown (2002a) found that the majority of Year 11 students defined studying or learning with surface strategies or methods (i.e., revision, re-reading, and reviewing of the year's work) and strongly agreed that learning involved building up knowledge by getting facts and information.” (Hattie y Brown, 2004, p. 2)

Entrando a mayor profundidad en la evaluación, Hattie y Brown, subrayan la diferencia entre la percepción que tienen los estudiantes sobre el aprendizaje, y como estos se inclinan por el enfoque superficial, mientras que los profesores optan por un tipo de aprendizaje profundo en los procesos de enseñanza. Estas dos categorías aprendizaje superficial y profundo, permiten generar la taxonomía de SOLO y en consecuencia un tipo de evaluación basada en los niveles uniestructural, multiestructural, relacional y abstracto ampliado.

El modelo taxonómico de SOLO planteado por Biggs, permite:

"When using the SOLO taxonomy, either the questions would be written in a differentmanner, or the test scorer would concentrate on classifying the responses only. An example of re-writing to maximise the correspondence between the question asked and the answer expected is seen in Figure 4".

Unistructural. Who painted Guernica?

Multistructural. Outline at least two compositiona principles that Pixasso used in Guernica.

Relational. Relate the theme of Guernica to ocurrent event.

Extended Abstract. Wahat do you consider Picasso was saying via his painting of Guernica?

Figure 4. SOLO Taxonomy Applied to Question/ Tasks about Picasso Guernica Fuente: COGNITIVE PROCESSES IN asTTle: The SOLO TAXONOMY.4.” (Hattie y Brown, 2004, p. 5)

El ejercicio de clasificación de la prueba que es mencionado en la cita anterior, significa que existe una relación directa y proporcional entre cada uno de los niveles de la prueba, es decir, el estudiante podrá ir mejorando el nivel de competencia en función del esfuerzo sistemático que este haga de la mano del profesor.

"La taxonomía SOLO se basa en el estudio de los resultados de distintas áreas académicas de contenido (Biggs y Collis, 1982). A medida que los estudiantes aprenden, los resultados de su aprendizaje muestran fases similares de creciente complejidad 
estructural. "Hay dos cambios principales dice Biggs- los cuantitativos, a medida que aumenta la cantidad de detalles principales en la respuesta de los estudiantes y cualitativos, a medida que los detalles se integran a un modelo estructural. Las fases cuantitativas del aprendizaje se producen primero; después, el aprendizaje cambia cualitativamente". (The flipped, woojssep. 2018. Párr. 1)

Ya entendido el proceso didáctico de la prueba y las implicaciones que esta tiene para el desarrollo progresivo de las competencias. Se presentan los diferentes elementos que componen las preguntas de manera teórica, junto a una aplicación didáctica desarrollada en la Universidad Cooperativa de Colombia. ${ }^{1}$

\subsubsection{Resultado didáctico}

Cuadro 1. Descripción general de la composición del contexto y los ítems.

\begin{tabular}{ll}
\hline Elemento de la prueba SOLO & Descripción de los elementos constitutivos \\
\hline Contexto & $\begin{array}{l}\text { Representación mental de una situación compleja del mundo real, } \\
\text { con diversos actores, roles e intereses, que se expresa mediante } \\
\text { textos, gráficos, tablas, imágenes y otros formatos, alrededor de } 400 \\
\text { palabras. }\end{array}$ \\
\hline Ítem Uniestructural & $\begin{array}{l}\text { Enunciado simple y directo (alrededor de } 6 \text { palabras) opciones con } \\
\text { una palabra preferible sustantivo concreto que se halla literalmente } \\
\text { en el texto. }\end{array}$ \\
\hline Ítem Multiestructural & $\begin{array}{l}\text { Enunciado simple y directo (alrededor de 10 palabras) opciones con } \\
\text { una lista de elementos relevantes de un concepto; los elementos se } \\
\text { hallan literalmente en el texto. }\end{array}$ \\
\hline Ítem relacional & $\begin{array}{l}\text { Enunciado con conectores de relación (alrededor de 12 palabras). } \\
\text { Opciones con inferencias y conceptos que demuestran una estructura } \\
\text { de explicación, interpretación, argumentación o comparación. }\end{array}$ \\
\hline Ítem abstracto ampliado & $\begin{array}{l}\text { Enunciado complejo con inferencias (alrededor de 15 palabras). } \\
\text { Opciones con múltiples inferencias comparaciones y contrastes } \\
\text { detallados y precisos, que generalizan. }\end{array}$ \\
\hline
\end{tabular}

Fuente: Diplomado Concepción y construcción de instrumentos de evaluación de competencias. Dr. Daniel Bogoya.

Teniendo en cuenta el anterior aporte, se elaboró una didáctica que permitiera el desarrollo de una plantilla para el acercamiento a la construcción de las preguntas de la prueba. Esta estrategia muestra una división estructural pertinente que corresponde a criterios: métrico, sintáctico, semántico, de coherencia y de validación textual.

1 Los siguientes ejercicios hacen parte del Diplomado Concepción y construcción de instrumentos de evaluación de competencias. Universidad Cooperativa Sede Pereira. Fecha: 27 de julio de 2018. 
La distribución por criterios permite generar proposiciones coherentes con los principios de la taxonomía SOLO, en relación a la experiencia de construcción de la pregunta, bajo especificidades pertinentes.

\begin{tabular}{|c|c|}
\hline ELEMENTOS & DESCRIPCIÓN DIDÁCTICA \\
\hline CONTEXTO & $\begin{array}{l}\text { Criterio métrico: de } 400 \text { a } 415 \text { palabras. } \\
\text { Criterio narratológico: Representación mental } \\
\text { escrita de una situación compleja del mundo real } \\
\text { o ficticio, con diversos actores, roles e intereses } \\
\text { enmarcados en una estructura narrativa. }\end{array}$ \\
\hline ÍTEMS UNIESTRUCTURALES & ÍTEM UNIESTRUCTURAL \\
\hline $\begin{array}{l}\text { Criterio métrico del ítem: } 6 \text { a } 9 \text { palabras. Buscar } \\
\text { elementos literales. }\end{array}$ & $\begin{array}{l}\text { Criterio sintáctico de las respuestas: un sólo } \\
\text { artículo con su respectiva palabra. }\end{array}$ \\
\hline $\begin{array}{l}\text { Criterio semántico del ítem: oración simple en } \\
\text { presente indicativo. }\end{array}$ & $\begin{array}{l}\text { Criterio de coherencia (principio de no } \\
\text { contradicción): verificación en el texto por código } \\
\text { de colores. }\end{array}$ \\
\hline $\begin{array}{l}\text { Criterio semántico de las respuestas: artículos } \\
\text { masculinos y femeninos. } \\
\text { Criterio sintáctico del ítem: un sujeto y un verbo. } \\
\text { Y la respectiva verificación en el campo semántico } \\
\text { escogido. }\end{array}$ & $\begin{array}{l}\text { Criterio de validación: por pares para contenido } \\
\text { y mediante teoría respuesta, al ítem para la } \\
\text { estadística. }\end{array}$ \\
\hline ÍTEMS MULTIESTRUCTURALES & ÍTEM MULTIESTRUCTURAL \\
\hline $\begin{array}{l}\text { Criterio métrico del ítem: } 9 \text { a } 12 \text { palabras. Buscar } \\
\text { elementos literales. }\end{array}$ & $\begin{array}{l}\text { Criterio de coherencia (principio de no } \\
\text { contradicción: verificación en el texto por código } \\
\text { de colores. }\end{array}$ \\
\hline $\begin{array}{l}\text { Criterio semántico del ítem: oración simple en } \\
\text { presente indicativo. }\end{array}$ & $\begin{array}{l}\text { Criterio de validación: por pares para contenido } \\
\text { y mediante teoría respuesta, al ítem para la }\end{array}$ \\
\hline $\begin{array}{l}\text { Criterio semántico de las respuestas: opciones } \\
\text { con una lista de elementos relevantes de un } \\
\text { concepto; los elementos se hallan literalmente en } \\
\text { el contexto. }\end{array}$ & $\begin{array}{l}\text { estadística. } \\
\text { Criterio sintáctico: un sujeto y un verbo. Y la } \\
\text { respectiva verificación en el campo semántico } \\
\text { escogido. }\end{array}$ \\
\hline
\end{tabular}

Figura 3. Muestra de Plantilla didáctica para elaboración de preguntas uniestructurales, multiestructurales y relacionales y abstractas.

Fuente: elaboración propia. Asesoría: M.Sc. Johann Leonardo Campos. Dr. Daniel Bogoya.

\section{DISGUSIÓN}

La discusión se centra en la falta de cohesión entre los elementos del currículo, ya que se requiere la integración de las didácticas con los procesos evaluativos para generar procesos educativos verificables pero contextualizados, por ello, si se realiza 
una aplicación didáctica y progresiva de la metodología SOLO de Biggs, bajo la premisa que los procesos de verificación del aprendizaje tenderán a mejorar en el tiempo: el requisito para que eso se cumpla será la articulación al plan de estudio de manera transversalizada a las didácticas, y al mismo método de evaluación, es decir, este tipo de preguntas se deben incorporar a las evaluaciones al interior del aula de clase, previo aprestamiento en la teoría a los estudiantes. De lo contrario se caería en un activismo sin contexto, que desconoce tanto el mundo de la vida, además del cómo aprende el profesor y el estudiante, negándose así la posibilidad de la adaptación progresiva de un modelo evaluativo clásico, a uno de progresión racional, como bien lo plantea Biggs, en el desarrollo de su método evaluativo.

\section{CONGLUSIONES}

Desde el análisis propuesto, el aprendizaje es un acto mediado por los sentidos, que tiende a ser exteriorizado a través del ejercicio de la búsqueda del origen del conocimiento, mediante el logro de un enfoque más profundo en la enseñanza por parte del profesor, en relación al aprendizaje del estudiante. Entendiendo que existe un proceso de correlación permanente entre en mundo de la vida (Husserl y Heidegger) determinado por la escuela y la sociedad, las relaciones de codependencia entre estudiantes, profesores y comunidad, que son manifiestas en el estar en el mundo (Heidegger) y el tejido de las relaciones intersubjetivas señalado por Habermas, que sin lugar a dudas es lo que permite la relación alumno-maestro, en un proceso de enseñanza-aprendizaje cercano a la vida, sin negar la posibilidad de la generación del conocimiento en y desde lo cognitivo.

La educación hace parte del mundo de la vida (Husserl y Heidegger), ya que al estudiante se le educa para ser competente en este, y quienes piensan la pedagogía, la didáctica y la evaluación, están actuando más en el mundo de la teoría para afectar mediante las relaciones intersubjetivas, que provienen del universo fenomenológico relacional, la vida de los estudiantes. Por ello es importante la generación de estrategias de investigación, que como es el caso de la metodología hermenéutica, Gademariana, puedan presentarse como la posibilidad de entender la filosofía, junto a la pedagogía, como una vez Aristóteles y Platón las entendieron, como posibilidad de transformación y emancipación de lo humano en relación a la evaluación, vinculada al proceso de educativo per se.

El resultado didáctico presenta la descripción general de la composición del contexto y los ítems junto al paso a paso a seguir para lograr la construcción de cada elemento de la prueba SOLO, es decir, se presenta estructuralmente un tipo de didáctica que le permite al educador construir las preguntas, teniendo en cuenta la métrica, el campo semántico y el contenido, además de los tipos de enunciados que este debe construir para generar preguntas de orden Uniestructural, Multiestructural, relacional y abstracto ampliado, este aspecto facilita el diseño de la estructura 
superficial y profunda de la pregunta, en relación al nivel de medición propuesto. Los criterios semántico y sintáctico, apoyan dichos procesos guiando al constructor del ítem, por el camino correcto para la construcción de este.

Los tipos de evaluación de orden cualitativo o cuantitativo por separado, no son suficientes para desarrollar mediciones fiables de los avances cognitivos en los estudiantes, la taxonomía de SOLO aplicada al proceso de educación por competencias, permite desarrollar progresivamente, procesos cognoscitivos rudimentarios (Escala uniestructural, multiestructural) hasta lograr tipos de razonamiento superior, como ocurre al resolver preguntas de carácter relacional y abstracto ampliado, teniendo como consecuencia que el mismo ejercicio evaluativo, genera apoyo a las didácticas de aula y al currículo, en la medida en que el estudiante logre los avances para alcanzar la competencia.

El mundo evaluativo desde la pedagogía, es interpretado a través de la investigación como la unión entre el campo de la filosofía, enfocado en el tránsito del mundo de la teoría, al mundo de la vida. Y al campo de la pedagogía, centrado en el aprendizaje como elemento neural del proceso educativo. Esto quiere decir, que tanto la enseñanza como el aprendizaje deben dotar al estudiante de los procesos cognitivos, práxicos y éticos necesarios, para desempeñarse adecuadamente en el periodo histórico que vive, asumiendo que el currículo por competencias es una opción pertinente para lograr pasar de la escuela a la sociedad, con las competencias necesarias para enfrentar la vida.

\section{BIBLIOGRAFÍA}

Alcaraz, Salarirche, Noelia (2015). Aproximación Histórica a la Evaluación Educativa: de la Generación de la Medición a la Generación Ecléctica. Revista Iberoamericana de Evaluación Educativa, n. 8, pp. 11-25.

Alcañiz, Mercedes (2008). Cambios demográficos en la sociedad global. vol.14 n .57. Párr. 39. Revista Papeles de población n. 14 pp. 227-256.

Biggs, John (2006). Calidad del aprendizaje universitario. Madrid: Narcea S.A Ediciones España.

Chacón, Policarpo y Covarrubias, Francisco (2012). Sustrato platónico de las teorías pedagógicas. Revista tiempo de educar. n. 25, pp. 140-59.

Dijk, Teun van (1980). Texto y contexto, semántica y pragmática del discurso. Madrid: Cátedra.

Habermas, Jürgen (1999). Teoría de la acción comunicativa I. España: Grupo Santillana de Ediciones, S. A.

Hattie Gavin, John and Brown TL, Gavin, New Zealand. Ministry of Education, Auckland UniServices, University of Auckland (2004). Assessment Tools for Teaching and 
Learning Technical [en línea], núm. 43, text 1-43. Disponible en: https://auckland. rl.talis.com/items/FCAC960F-E73F-5558-0946-73168F2E0E1B.html

Herrera Restrepo, Daniel (2010). Husserl y el mundo de la vida. Revista de las ciencias del espíritu, n. 4, 52, pp. 247, 248. https://doi.org/10.21500/01201468.939

Husserl, Edmund (1999). IDEAS relativas a una fenomenología pura y una filosofía fenomenológica. México: Fondo de Cultura Económica.

León Lázaro, Guillermo de (2013). La educación en Roma. Anuario Jurídico y Económico Escurialense, n. 6, pp. 469-480.

Lizcaino Dallos, Adriana, et al. (2017). Competencias digitales, innovación y prospectiva. Colombia: CIMTED.

Locke, John (2012). Pensamiento sobre la educación. Madrid: Alkal.

McDonald, Rod; Boud, David y Francis, John (2000). Nuevas perspectivas sobre la evaluación. Boletín Técnico Interamericano de Formación Profesional, [En línea], núm. 149, texto, 41-72. Disponible en: www.oitcinterfor.org/sites/default/ files/file articulo/rodajog.pdf

Monzón Troncoso, Martha Yolanda. Evaluación del aprendizaje: un recorrido histórico y epistemológico (2015). Revista de ciencias de la educación, n. 6, pp. 12-24.

Mora Vargas, Ana Isabel (2004). La evaluación educativa: concepto, períodos y modelos. Revista Electrónica “Actualidades Investigativas en Educación”, n. 4, pp. 1-28.

Noriega Rodríguez, Yajaira. (2002). La hermenéutica aplicada a la interpretación del texto. El uso de la técnica del análisis de contenido. Revista de ciencias de la educación, n. 2, pp. 1-8.

Obando Bastidas, Jhon (2014). Evaluación de competencias. Revista Memorias, n. 4, pp. 12, pp.73-79.

Pardo Camillo, Reyna Guadalupe et al. (2013). La evaluación en la escuela. Secretaría de Educación Pública, [en línea], núm. 1, texto 3-192. Disponible en: https://www2. sepdf.gob.mx/formacion_continua/antologias/archivos-2014/SEP220021.pdf

The Flipped, Woojssep. (2018). La taxonomía SOLO de Biggs. Proyecto The Flipped Classroom [en línea], núm. 1, texto 1-2. Disponible en: https://www. theflippedclassroom.es/la-taxonomia-solo-de-biggs/

Tyler, Ralph (1986). Principios básicos del currículo. Buenos Aires: Troquel.

Unigarro Gutiérrez, Manuel Antonio (2017). Un modelo educativo crítico con enfoque de competencias. Bogotá: Universidad Cooperativa de Colombia.

Vargas Leyva, María Ruth (2008). Diseño curricular por competencias. México: Tecnológico de Estudios Superiores de Ecatepec.

Villa Prieto, Josué (2014). La enseñanza en la universidad medieval. Centros, métodos, lecturas. Revista tiempo y sociedad, n. 26, pp. 59-131. 
Evaluación por competencias en campos de conocimiento... - J. Jairo Mosquera

Zygmunt, Bauman (2013). La cultura en el mundo de la modernidad líquida. México: Fondo de Cultura Económica. 